the most prominent teaching establishment in the world. There is not a single point of interest connected with the cropping and manuring of the land, the forming and treatment of pastures, and the feeding of animals, which has not been made the subject of exhaustive experiment at Rothamsted, while the silo experiments which have been lately undertaken for the purpose of testing the value of ensilage, will probably do more for the instruction of those land-proprietors and large farmers who are watching them than all else which has been said or done in regard to this much-praised cattle food. It would be strange indeed if agriculturists refused to listen to Sir John Lawes, but although certain facts of prime importance in the long catalogue of useful lessons from Rothamsted have been widely distributed, the voluminous writings of the great experimenter, trusted as he is, are not read by one per cent. of those on whose behalf they were undertaken. Some of the more important teachings of Rothamsted have become so familiar that they have passed into agricultural axioms, such as "phosphorus for turnips, nitrogen for corn." We have ourselves known farmers who have travelled a hundred miles-a long flight for such men-for the purpose of seeing for themselves at Rothamsted how corn might be grown continuously by means of small dressings of nitrogenous manures, and thus they have solved a problem of vital importance to themselves and their families. But comparatively few farmers will trust themselves so far from home, even on a matter of life and death, and it has become a business of grave importance to the rent-receiving portion of the landed interest to convey to the rank and file of tenant farmers the necessary knowledge which they are too inert and ignorant to acquire for themselves.

In the hope of teaching farmers, the Royal Agricultural Society, the Bath and West of England Society, some landlords in Sussex, and others, are endeavouring to increase the number of experimental farms. Minds that are entirely untrained or ignorant can only be taught orally or by imitation. Put an attractive story into the hands of an ill-instructed boy, and he will soon lay the book aside; but, read or relate the story to him, and he will probably be found a fascinated listener. It is the same with farmers and scientific farming. They cannot learn from books, but they will listen to the story by word of mouth. The leading agricultural societies are therefore making a timely move in considering the best methods of teaching farmers by example-that is, by the multiplication of experimental farms. Lectures delivered by professors, and listened to with stubborn incredulity, are of little use compared with experiments tried by the roadside and discussed at the market tables of the neighbourhood. It is gratifying to notice, therefore, that at a recent Council meeting of the Royal Agricultural Society a new departure was announced in the appointment of a committee to consider how the National Society could best co-operate with local societies in carrying out investigations into subjects of practical utility in agriculture. An additional reason for multiplying stations is that, in consequence of the variation of climate and other causes, farming is conducted under different conditions in the several districts. In one locality, for example, the special problem to be solved may concern the management of grasses, in another that of corn. In all alike the object of the teachers of agriculture must be to substitute, so far as may be possible, the rule of three for the rule of thumb at present in vogue.

At Rothamsted the experiments of the past forty years have related to the growth of continuous crops year after year on the same land, to the growth of crops under rotation, to the use of every kind of artificial manure, or of farm-yard dung, in varying quantities on every kind of crop, and, for the sake of comparison, to the omission of all manure on some of the land, to the manuring of permanent pasture, fallowing, the use of various feeding stuffs, town sewage, the question whether plants assimilate free nitrogen, ensilage, rainfall, and the waste of nitrogen in land-drainage water. It has been stated that some of the elaborate investigations which have been conducted at Rothamsted are too "scientific" for humbler establishments. If by science we mean a complete knowledge of facts the phrase is hardly accurate, but no doubt some of the Rothamsted experiments were accompanied by the analyses of animals, plants, and soils, and could not therefore be repeated at ordinary stations. On the other hand, the most useful experiments for the instruction of farmers are those which relate to the effects of the different foods employed for plants and animals, and in these cases farmers can themselves form estimates of the results which will prove sufficiently accurate for practical purposes and may lead to the saving of millions which are now annually wasted through the ignorant use of manures and improper feeding of animals.

H. E.

\section{ELECTRICITY AT THE INVENTIONS EXHIBITION}

The Secondary Generators of Messrs. Gaulard and Gibbs

HITHERTO there have been two means employed for electric illumination and the electric transmission of energy-viz. supplying the electricity required for the lamps or other receivers (I) direct from the dynamo machines, and (2) from secondary batteries charged by means of dynamos. A third method has been recently introduced, by means of secondary generators, of which a small installation has been made at the Inventions Exhibition, to which we propose to refer in this article.

The object of this invention is to supply a current which may be varied at will both as regards electromotive force and quantity, and thus be made applicable to work at the same time arc lamps, incandescent lamps, and motors. The means by which this result has been effected is by interposing between the dynamo machine and the lamp or other receiver of electricity a supplementary apparatus, by the use of which an induced current is produced proper to the particular receiver which it is desired to work.

The National Company for the Distribution of Electricity by Secondary Generators, which works the patents of Messrs. Gaulard and Gibls, originally used secondary generators of the following construction. They were composed of a thick insulated copper wire, surrounded by smaller coils formed of a number of thin insulated copper wires; the thick central wire receiving the current from the dynamo, which was distributed through the secondary wires. This method of construction has been replaced by one of exceeding simplicity, in which the difficulty of insulation and complication of manufacture of the original form are done away with.

The conductor for the primary current and the conductor in which the induced current is produced consist of a series of annular disks of sheet copper $\frac{1}{4}$ millimetre in thickness and $3 \frac{1}{2}$ centimetres in width, slit across at one part and furnished with projecting pieces extending outwards on either side of the slit. The conductor for the primary circuit is made up of a series of these annular disks, and the conductor for the induced current is made up of a second similar series, the two series being so interlaced that the convolutions of the helix formed by the disks for the primary circuit alternate with the convolutions of the helix formed by the disks of the induced circuit. An annular disk of insulating material, such as paraffined cardboard, is placed between each convolution of the double helix thus formed, so as to prevent short circuiting between the helices and the several convolutions thereof, and the projecting pieces of all the disks for the primary current are soldered or electrically connected together, and the projecting pieces of all the disks 
for the induced current are similarly electrically connected. In constructing the secondary coils, they are fixed together between two insulating surfaces by bolts and nuts, the projections by which the several conducting disks are connected projecting helically or spirally around the coil (the projections of the primary alternating with those of the secondary coil), and form convenient means for connecting up any number of convolutions as required.

The end disks of one of the helices thus formed are connected to the leads of the primary circuit by bindingscrews, and the end disks of the other helix are similarly connected to the leads for the induced or secondary current. In the centre of the disks is a hollow cylinder of paraffined cardboard or other suitable insulating material, around which the helices are arranged, and in this cylinder is a core of soft iron, or of soft iron wires, which is capable of being automatically raised and lowered in the cylinder, so as to regulate as required the current passing through the coil.

The main wire from the dynamo is connected up in series to the primary helices of a group of secondary generators, and, in passing through the primary helices, induces a current in the secondaries, the tension of which, according to the experimental investigations of the inventors, increases first with the intensity or quantity of the primary current, and, secondly, with the rapidity of the interruptions or alternations, or the variations of its potential. Each secondary generator forms a complete installation, and can be put in or out of circuit at pleasure. The secondaries may be connected up in series, in multiple arc, or in multiple series, as desired, the connections being readily altered by means of a switch-board ; tension or quantity is thus obtained according to the nature of the current required. The lamps or other receivers fed from the secondary generator can be connected at will to their respective circuits, and are also independent of one another.

These generators are made to work in connection with alternate-current machines, because the latter can be constructed up to almost any power, as no two parts of the machine having great difference of potential need be in close proximity, and the alternation of current may be made as quickly as desired. The generating dynamo is so constructed and operated that the quantity of current is preserved constant, and the tension is varied to carry this current through the primary conductor against the varying counter electromotive force due to variations in the work done in the secondary circuits of a number of secondary generators. If $W$ represents work, $C$ current, $E$ electromotive force, and $R$ resistance, and if either of these factors be changed, the others must be altered in the same ratio, according to the formula-

$$
W=C E=C^{2} R=\frac{E^{2}}{R},
$$

if uniform effects in the secondary circuits are to be desired.

One of the chief characteristics of this system is that if the primary current be kept constant the loss due to resistance remains fixed, no matter what energy is transmitted-so that if an increase of energy is desired, the only factor that has to be increased is the electromotive force, which bears no ratio to the loss in the conductor. This circumstance is of importance in any house-to-house lighting scheme, where a conductor may be laid down to supply a certain area, and if the lights are not taken up at once, the necessary current can be supplied later within the limits of the dynamo, by increasing the electromotive force, without increasing the size of the conductor, the strength of the current, or the loss in the line.

As regards the very high potential required upon the secondary generator system, the danger is limited to the supply station, as between the two poles of the main dynamo there is an unbroken metallic circuit, which maintains the continuity of the flow of current; and as regards each secondary circuit the work done is represented by a secondary generator, and the only danger would be in grasping both primary terminals at once, which may be made impossible of performance. It will be necessary as regards the dynamo that it shall be insulated from the earth, and also that such parts of the circuit as carry high tension electricity shall be so protected that it shall be impossible to make contact between them and the earth.

In comparing this system, in which there is a loss in the transformation of the energy by the secondary generator, with the direct system, this loss will have to be balanced against that caused by resistance due to distance, whilst as regards the regulation of the supply of energy, this is effected by means of a regulator working the exciting machine of the dynamo at the station; by its means, when a secondary generator is cut out of circuit, a proportionate amount of power is saved. The secondary generators also regulate the energy absorbed, so that a perfect control of power is obtained, which is especially important for domestic supplies of electricity, as, when a suitable current measurer has been designed, consumers will be able to pay simply according to the amount consumed.

At present the extreme northern end only of the East Arcade at the Exhibition is being lighted on this system; it is proposed, however, to extend it to the full length of the East Arcade and to the concert-room.

\section{THE AFGHAN DELIMITATION COMMISSION}

$\mathrm{WE}$ are indebted to the courtesy of the Kew authorities for the opportunity of publishing the accompanying letter from Surgeon-Major Aitchison, C.I.E., F.R.S., which gives the most recent account of his work as naturalist to the Expedition:-

\section{Camp Tir-Phul, Northern Afghanistan, 6 miles from Khusan}

\section{DeAR Sir Joseph HoOkER,- -}

I am now able to write to you with some pleasure, as I have been able to put together this year some 300 species in all. The last 100 I obtained on a ten days' trip that I made from this camp. I left this on April 25 under very bad auspices, as it had blown all night and was blowing a terrible gale with every chance of a heavy fall of rain from the north. But I started and got as far as Khusan, in the vicinity of which, beside the ruins of an old "serai," I halted. I picked up a few odds and ends, the chief attraction was the Rosa margerita (if a new sp.) mihi. It covers the whole country in localised patches, and being very dwarf in habit, not above 2 feet, the flowers are seen to perfection ; they open out expanding almost flat, when the brilliant eyes, formed by the claret colour of the bases of the petals, gives it quite a character. Amongst my rose hips sent to you last year this was one of the species. I hope to be able to supply you with a lot more, it would make a lovely flower border.

I marched next to a place on the right bank of the Harirúd River opposite Tomăn-ághá, fifteen miles. Our route lay over a plain that had once been the bed of the river where the river had made a great bend; the river, after silting up this bend, had left it. The most characteristic plant here was a Rhubarb, usually with 3-root leaves of immense proportion for the size of the flowering stem; these leaves are so pressed flat to the ground that it reminds one more of the Victoria regia leaves (without the margin), and this is the habit of the plant; the plant was fruiting, having large winged fruit of a most brilliant scarlet; it will make a grand thing in gardens. The 